\title{
Long-term survival in a patient with repeated resections for lung metastasis after hepatectomy for ruptured hepatocellular
} carcinoma: a case report Kai-Lun Shih ${ }^{* 1}$, Yang-Yuan Chen ${ }^{1}$, Tsung-Han Teng ${ }^{2}$ and Maw-Soan Soon ${ }^{1}$

Address: ${ }^{1}$ Department of Gastroenterology Changhua Christian Hospital, Changhua, Taiwan and ${ }^{2}$ Department of Pathology, Changhua Christian Hospital, Changhua, Taiwan

Email: Kai-Lun Shih* - 107400@cch.org.tw; Yang-Yuan Chen - 27716@cch.org.tw; Tsung-Han Teng - 130993@cch.org.tw; Maw-

Soan Soon-2531@cch.org.tw

* Corresponding author

Published: 30 June 2008

Journal of Medical Case Reports 2008, 2:222 doi:10.1186/1752-1947-2-222

This article is available from: http://www.jmedicalcasereports.com/content/2/1/222

(c) 2008 Shih et al; licensee BioMed Central Ltd.

This is an Open Access article distributed under the terms of the Creative Commons Attribution License (http://creativecommons.org/licenses/by/2.0), which permits unrestricted use, distribution, and reproduction in any medium, provided the original work is properly cited.
Received: 7 December 2007

Accepted: 30 June 2008

\begin{abstract}
Introduction: Tumor rupture and pulmonary metastasis in patients with hepatocellular carcinoma are both associated with poor prognosis and treatment strategies are controversial.

Case presentation: Here we report a 50 -year-old man with survival of over 90 months after undergoing an extended right lobectomy for a ruptured hepatocellular carcinoma and then repeated resections for pulmonary metastasis during the followup period.
\end{abstract}

Conclusion: This case report shows that surgical resection can be an effective treatment for patients with both ruptured hepatocellular carcinoma and pulmonary recurrences.

\section{Introduction}

Hepatocellular carcinoma (HCC) is the most common primary hepatic tumor and one of the most common cancers worldwide. Spontaneous rupture is a life-threatening complication of HCC. The overall incidence of spontaneous rupture of HCC varies from $5 \%$ to $26 \%$, with a mortality rate of up to $67 \%$, especially in patients with poor liver function [1-4].

The treatment of a ruptured HCC is controversial. Previous studies have suggested that emergency liver resection is feasible in patients with a small tumor and satisfactory liver function (Child-Pugh A or B grade). Surgical resection is currently the only way to achieve long-term survival [5].
The lung is the most common site of metastasis in patients with HCC. These are often unresectable as most pulmonary metastases are multiple [6]. Nevertheless, some studies have revealed that surgical resection of pulmonary metastases from HCC may prolong survival in selected patients [7-9]. Ruptured HCC often exacerbates the risk of disseminated intraperitoneal metastases, and previous studies have suggested long-term survival may be possible with aggressive surgical treatment, even if intraperitoneal metastases develop $[10,11]$. However, to our knowledge there has been no report of a patient who has undergone resections of pulmonary metastasis after hepatectomy for a ruptured HCC. Here we report a rare case of long-term survival after three pulmonary metastasectomies following hepatectomy for a ruptured HCC. 


\section{Case presentation}

On 23 February 2000, a 50-year-old man was referred to our hospital because of progressive abdominal pain for 3 hours. The patient's initial blood pressure was $88 / 58$ $\mathrm{mmHg}$ and his heart rate was 109 beats/minute. Laboratory data were within normal limits except for the hemoglobin and alanine aminotransferase, which were $8.8 \mathrm{~g} / \mathrm{dl}$, and $145 \mathrm{U} / \mathrm{l}$, respectively. After transfusion of 2 units of packed red blood cells and 4 units of fresh frozen plasma, the patient's blood pressure was $112 / 63 \mathrm{mmHg}$ and his heart rate was 75 beats/minute. Abdominal computed tomography (CT) on admission showed a $12 \times 12.5 \times 5$ $\mathrm{cm}^{3}$ mass in Couinaud segments 7 and 8 and ascites accumulation (Figure 1). Angiography revealed dilated, tortuous and displaced arterial tumor feeders with neovasculatures showing a disorganized pattern over the right lobe of the liver. This was consistent with HCC. Other laboratory data revealed positive hepatitis B virus surface antigen and antibodies against hepatitis $C$ virus. Serum alpha-fetoprotein level was less than $20 \mathrm{ng} / \mathrm{ml}$.

The patient underwent a right extended lobectomy, with partial resection of the diaphragm (about $4 \times 4 \mathrm{~cm}^{2}$ ) and cholecystectomy, on 26 February 2000. The tumor was resected with margins greater than or equal to $1 \mathrm{~cm}$. Six

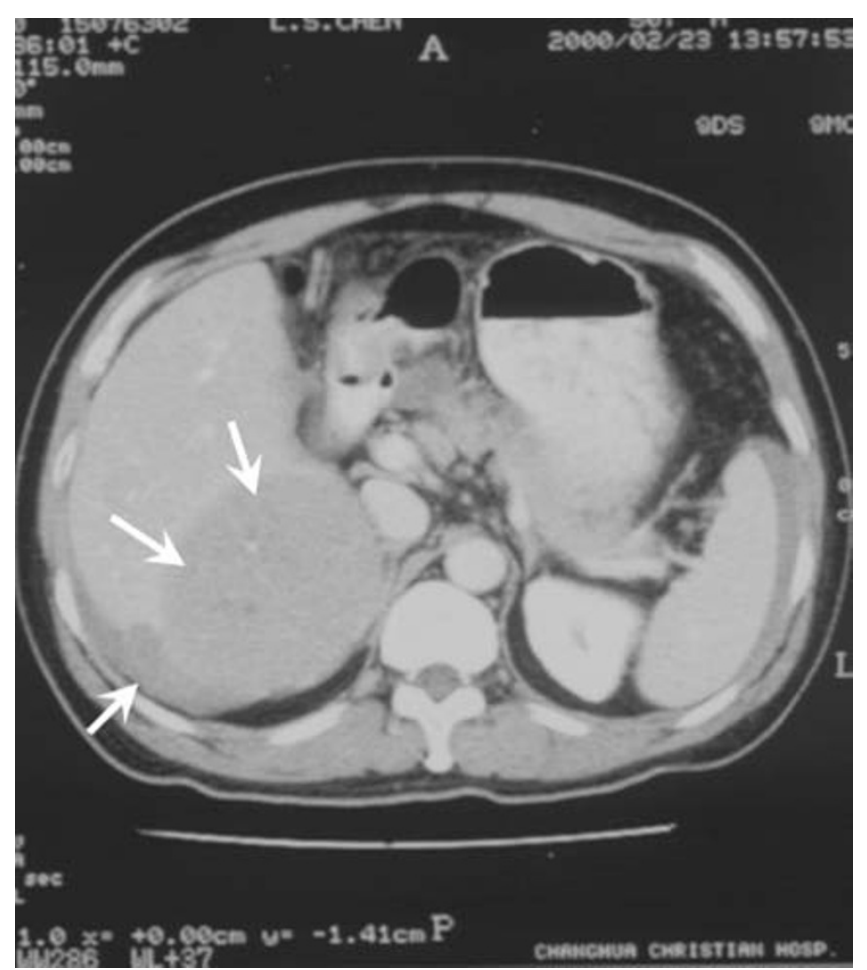

Figure I

Abdominal computed tomography on admission showing a mass in Couinaud segment 7 and segment 8 of the liver and intraperitoneal fluid. hundred cubic centimetres of bloody ascites were removed during surgery.

Histopathological examination revealed a poorly differentiated HCC (Figure 2a). Direct invasion to the resected diaphragm was seen, although the microscopic surgical margins were unremarkable.

The patient's postoperative course was smooth and he was discharged on 13 March 2000. After surgery, he had regular followups with serum alpha-fetoprotein levels, chest radiographs, and abdominal ultrasonography every three months in our hospital. A small intrahepatic recurrence was found and treated twice by ultrasound-guided percutaneous alcohol injection.

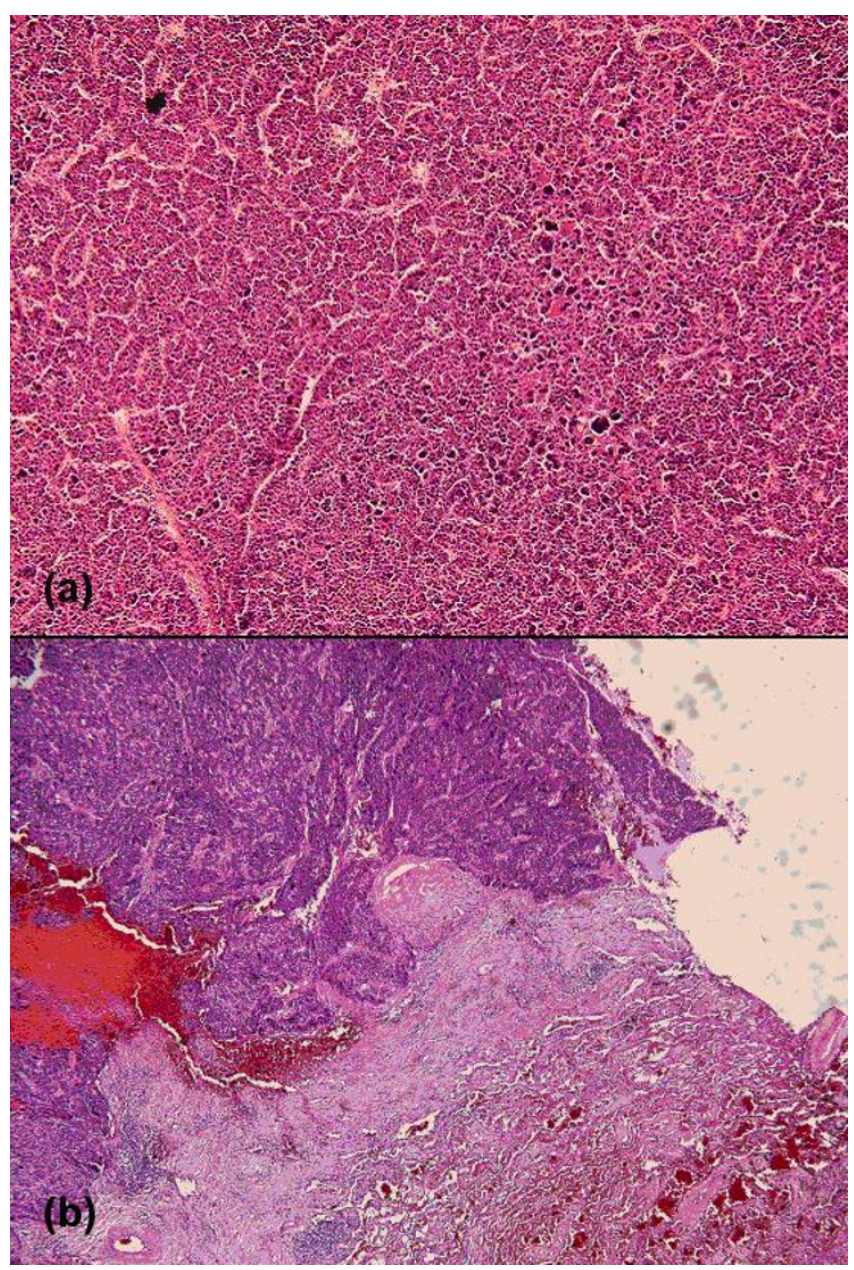

Figure 2

2a: Polygonal cells with higher N/C (nucleus-to-cytoplasm) ratio than normal, abundant granular eosinophilic cytoplasm, round nuclei with coarse chromatin and an area of giant cell (original magnification $\times 100$ ). $-2 \mathrm{~b}$ : Metastatic hepatocellular carcinoma in lung parenchyma (original magnification $\times 40$ ). 


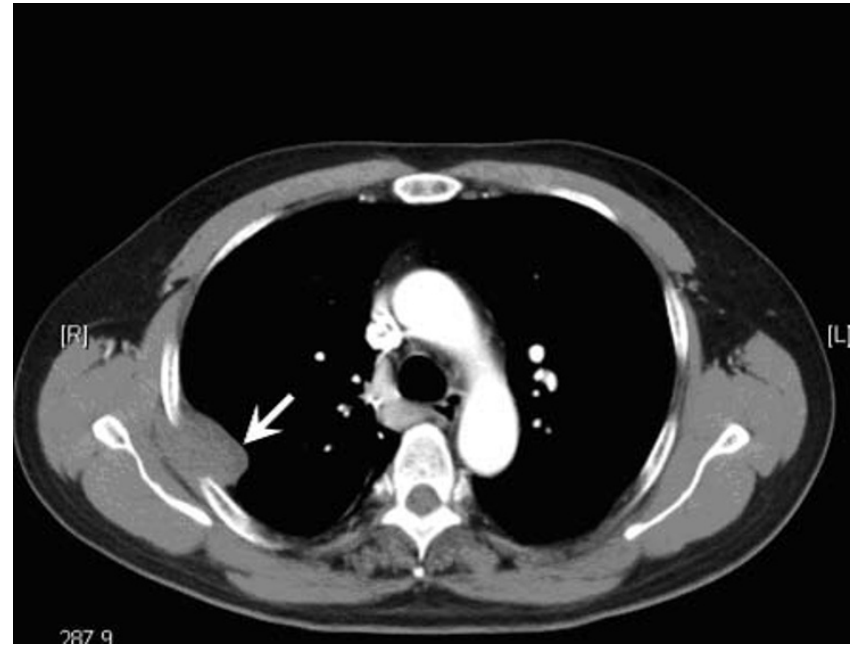

Figure 3

Chest computed tomography showing lung metastasis with pleural seeding 80 months after hepatectomy.

The patient presented with mild hemoptysis 30 months after the hepatectomy, and follow-up chest CT demonstrated a metastasis in the right lower lobe the of lungs. The metastasis was removed with wedge resection measuring $2 \times 1 \times 1 \mathrm{~cm}^{3}$. Histopathological examination confirmed the presence of metastatic HCC (Figure 2b).

A follow-up chest radiograph and CT revealed a $2.9 \mathrm{~cm}$ solitary metastasis in the right upper lobe of the lung without any sign of liver recurrence 52 months after hepatectomy. A wedge resection of the right upper lobe of the lung was performed through a thoracotomy and the tumor was confirmed as a metastasis of HCC.

A further follow-up chest CT scan disclosed tumor recurrence in the right upper lobe of the lung and pleural seeding 80 months after hepatectomy (Figure 3). The serum alpha-fetoprotein level was $39.14 \mathrm{ng} / \mathrm{ml}$. The patient underwent surgery again in December 2006 and these tumors were removed with combined resection of the right upper pulmonary lobe and right chest wall with the fourth and fifth ribs. Histopathological examination confirmed the presence of metastatic HCC. After surgery, the serum alpha-fetoprotein level decreased to $1.96 \mathrm{ng} / \mathrm{ml}$ in February 2007.

No intrahepatic recurrence of HCC was found after the last percutaneous alcohol injection of the liver and the patient has remained disease-free for 10 months since the last resection of pulmonary metastases, i.e. 90 months after the initial hepatectomy for a ruptured HCC.

\section{Discussion}

The exact mechanism of spontaneous HCC rupture is still unknown although hypotheses include rapid growth of tumor with necrosis, erosion of a vessel, occlusion of the hepatic veins by a tumor thrombus, and coagulopathy [12]. The prognosis of ruptured HCC is poor because many patients have advanced disease at the time of rupture and may also have cirrhosis. Malignant cells sometimes disseminate into the peritoneal cavity contributing to poor prognosis [1]. There have been few reports of successful resection of peritoneal and pleural disseminated metastases caused by a ruptured HCC $[11,13]$.

In our patient, HCC with direct invasion to the diaphragm was seen and was resected with clear margins, and intrahepatic recurrence was controlled by local ablation. Pulmonary metastases were diagnosed 30,52 , and 80 months after hepatectomy and were removed by repeated wedge resections.

The lung is the most common site for extrahepatic spread of HCC and leads to a poor prognosis [14]. Some authors suggest that an extrahepatic metastasis should be treated medically [15]. Previous literature described four criteria for pulmonary metastasectomy: [1] the patient must be a good risk for surgical intervention; [2] the primary malignancy must be controlled; [3] there should be no other extrapulmonary metastasis, or, if present, it can be controlled by surgery or another treatment modality; and [4] the pulmonary metastases are believed to be completely resectable $[16,17]$.

Some reports support the effectiveness of pulmonary resection of metastases from HCC. Tomimaru et al. [9] reported that surgical resection for pulmonary metastasis from HCC is beneficial on the condition that the number of lung metastases is limited to one or two, and any intrahepatic recurrence is well managed.

Factors for good prognosis after pulmonary metastasectomy of HCC include a patient's disease-free interval greater than 12 months and alpha-fetoprotein levels less than $500 \mathrm{ng} / \mathrm{ml}$ [8]. For our patient, the number of lung metastases during the third metastasectomy was two, and his alpha-fetoprotein levels returned to normal levels soon after the operation.

Few reports described long-term survival after resection of pulmonary metastases from HCC [18]. Our case report suggests that for a patient with HCC and pulmonary metastases, surgical resection for lung metastases can be effective if the number of lung metastases is less than two. 


\section{Conclusion}

This case report suggests that surgical resection can be an effective treatment for patients with both ruptured HCC and pulmonary recurrences. When intrahepatic recurrences are not present, a previous episode of HCC rupture is not a contraindication for pulmonary metastasectomy in patients with HCC.

\section{Abbreviations}

CT: computed tomography; HCC: hepatocellular carcinoma.

\section{Competing interests}

The authors declare that they have no competing interests.

\section{Authors' contributions}

KLS and YYC examined the patient, reviewed the literature, and wrote the manuscript. The manuscript was reviewed and edited by YYC and MSS. All authors read and approved the final manuscript.

\section{Consent}

Written informed consent was obtained from the patient for publication of this case report and any accompanying images. A copy of the written consent is available for review by the Editor-in-Chief of this journal.

\section{References}

I. Zhu LX, Wang GS, Fan ST: Spontaneous rupture of hepatocellular carcinoma. Br J Surg 1996, 83:602-607.

2. Yamagata M, Maeda T, Ikeda Y, Shirabe K, Nishizaki T, Koyanagi N: Surgical results of spontaneously ruptured hepatocellular carcinoma. Hepatogastroenterology 1995, 42:46I-464.

3. Chen CY, Lin XZ, Shin JS, Lin CY, Leow TC, Chen CY, Chang TT: Spontaneous rupture of hepatocellular carcinoma. A review of I4I Taiwanese cases and comparison with nonrupture cases. J Clin Gastroenterol 1995, 21:238-242.

4. Chen WK, Chang YT, Chung YT, Yang HR: Outcomes of emergency treatment in ruptured hepatocellular carcinoma in the ED. Am J Emerg Med 2005, 23:730-736.

5. Chiappa A, Zbar A, Audisio RA, Paties C, Bertani E, Staudacher C: Emergency liver resection for ruptured hepatocellular carcinoma complicating cirrhosis. Hepatogastroenterology 1999 , 46: II45-II50.

6. Katyal S, Oliver JH, Peterson MS, Ferris JV, Carr BS, Baron RL: Extrahepatic metastases of hepatocellular carcinoma. Radiology 2000, 21 6:698-703.

7. Nakajima J, Tanaka M, Matsumoto J, Takeuchi E, Fukami T, Takamoto S: Appraisal of surgical treatment for pulmonary metastasis from hepatocellular carcinoma. World J Surg 2005, 29:7I5-718.

8. Nakagawa T, Kamiyama T, Nakanishi K, Yokoo H, Kamachi H, Matsushita $M$, Todo S: Pulmonary resection for metastases from hepatocellular carcinoma: factors influencing prognosis. J Thorac Cardiovasc Surg 2006, I 3 1: 1 248- 1254.

9. Tomimaru Y, Sasaki Y, Yamada T, Eguchi H, Takami K, Ohigashi H, Higashiyama M, Ishikawa O, Kodama K, Imaoka S: The significance of surgical resection for pulmonary metastasis from hepatocellular carcinoma. Am J Surg 2006, 192:46-5I.

10. Ryu JK, Lee SB, Kim KH, Yoh KT: Surgical treatment in a patient with multiple implanted intraperitoneal metastases after resection of ruptured large hepatocellular carcinoma. Hepatogastroenterology 2004, 5 I:239-242.

II. Kaido T, Arii S, Shiota M, Imamura M: Repeated resection for extrahepatic recurrences after hepatectomy for ruptured hepatocellular carcinoma. J Hepatobiliary Pancreat Surg 2004, II:I49-152.
12. Liu CL, Fan ST, Lo CM, Tso WK, Poon RT, Lam CM, Wong J: Management of spontaneous rupture of hepatocellular carcinoma: single-center experience. J Clin Oncol 2001, 19:3725-3732.

13. Kosaka A, Hayakawa H, Kusagawa M, Takahashi H, Okamura K, Mizumoto R, Katsuta K: Successful surgical treatment for implanted intraperitoneal metastases of ruptured small hepatocellular carcinoma: report of a case. Surg Today 1999, 29:453-457.

14. Natsuizaka M, Omura T, Akaike T, Kuwata Y, Yamazaki K, Sato T, Karino Y, Toyota J, Suga T, Asaka M: Clinical features of hepatocellular carcinoma with extrahepatic metastases. J Gastroenterol Hepatol 2005, 20: I78I-I 787.

15. Aramaki M, Kawano K, Kai T, Yokoyama H, Morii Y, Sasaki A, Yoshida $\mathrm{T}$, Kitano S: Treatment for extrahepatic metastasis of hepatocellular carcinoma following successful hepatic resection. Hepatogastroenterology 1999, 46:2931-2934.

16. Thomford NR, Woolner LB, Clagett OT: The surgical treatment of metastatic tumors in the lungs. J Thorac Cardiovasc Surg 1965, 49:357-363.

17. Kondo H, Okumura T, Ohde Y, Nakagawa K: Surgical treatment for metastatic malignancies. Pulmonary metastasis: indications and outcomes. Int J Clin Oncol 2005, 1 0:8I-85.

18. Nakamura T, Kimura T, Umehara $Y$, Suzuki K, Okamoto K, Okumura T, Morizumi S, Kawabata T, Komiyama A: Long-term survival after report resection of pulmonary metastases from hepatocellular carcinoma: report of two cases. Surg Today 2000, 35(10):890-892.
Publish with Bio Med Central and every scientist can read your work free of charge

"BioMed Central will be the most significant development for disseminating the results of biomedical research in our lifetime. "

Sir Paul Nurse, Cancer Research UK

Your research papers will be:

- available free of charge to the entire biomedical community

- peer reviewed and published immediately upon acceptance

- cited in PubMed and archived on PubMed Central

- yours - you keep the copyright

Submit your manuscript here:

http://www.biomedcentral.com/info/publishing_adv.asp
BioMedcentral 